\title{
Registros periodísticos en la crítica de arte
}

\author{
Enrique MENA GARCÍA \\ Universidad de Murcia \\ enriquemena@hotmail.es
}

Recibido: 30 de septiembre de 2013

Aceptado: 14 de febrero de 2014

\section{Resumen}

Este análisis se adentra en esa crítica de arte en prensa junto con el criterio aplicado y difusión en la sociedad, desde unos preliminares puntos como la historia de la crítica, su posición nacional y regional, junto con un estudio dirigido al crítico actual en la prensa murciana. Este estudio formó parte del Proyecto Fin de Carrera cuando se finalizaba la licenciatura de Publicidad y Relaciones Públicas en la UM, revisado para la ocasión, en el cual se analizaba la visión crítica aplicada a las artes plásticas, sin extenderse a otros campos, y especialmente al periodo contemporáneo murciano.

Palabras clave: Crítica de Arte, Posmodernidad, Grupo Puente Nuevo, Prensa, Periodismo digital.

\section{Journalistic Records in the Critique of Art}

\begin{abstract}
This analysis delves into the art criticism in the press along with the approach and diffusion in society, from a few preliminary points as the history of criticism, national and regional position, along with a critical current study led to the press in Murcia. This study was part of the final project when it ended a degree in Advertising and Public Relations at UM, revised for the occasion, in which it was analyzed the critical view applied to the visual arts, not extended to other fields, especially the murcian contemporary period.

Keywords: Art Criticism, Postmodernism, New Bridge Group, Press, Digital Journalism.

\section{Referencia normalizada}

MENA GARCÍA, Enrique (2014): "Registros periodísticos en la crítica de arte”. Estudios sobre el Mensaje Periodístico. Vol. 20, Núm. 2 (julio-diciembre), págs.: 1131-1147. Madrid, Servicio de Publicaciones de la Universidad Complutense.
\end{abstract}

Sumario: 1. Introducción. 2. Evolución histórica. 3. La crítica y el crítico. 4. Panorama murciano. 5. Valoración. 6. Referencias bibliográficas.

\section{Introducción}

La crítica ofrecida en diarios afecta a lo efímero, ya que se hace eco de lo actual en mayor medida, aunque también se adentra en revisionismos, retrospectivas y antológicas, pero de igual forma quedan ahí, supeditadas al momento concreto. A veces con rescatadas reseñas de otra época, gracias a estudios, exposiciones o investigaciones de modo que de nuevo quedan vigentes. Una desolada vigencia que permanece en las hemerotecas de archivos y bibliotecas a la espera de un nuevo lector.

Es cierto que la comunicación visual de masas (Luhmann, N. 2000) abarca el cine, la fotografía, el cartel, el cómic, la televisión, Internet, donde se mantienen con dignidad las artes plásticas como la pintura y la escultura. Aquí tratamos la crítica en artes plásticas, sin extendernos a otros campos, y especialmente el periodo contemporáneo murciano.

Al realizar esta investigación dentro del campo de la "comunicación", quiero comenzar con la aseveración de John Dewey, según la cual, el arte es el mejor camino hacia el entendimiento de una cultura, además de, tanto la teoría de la expresión como 
la cognitiva sostiene que el arte comunica; puede comunicar sentimientos y emociones o pensamientos e ideas (Freeland, C., 2004: 160). Y según el sociólogo Abraham Moles, en su Sociodinámica de la Cultura, en su cuadro cultural están interrelacionados los creadores, los medios de comunicación y la sociedad.

Cierto es que los museos son el espacio público por antonomasia para mostrar obra de arte, comenzando con el padre de todos como fue el Louvre en 1793, pero el arte se ha hecho más cercano y paradójicamente también lejano, es decir, el arte desde los fenómenos que comienzan con el atrevido "happening" de John Cage en los cincuenta, pasando por lo Conceptual del arte hasta la década de 1960 con el Body Art, seguido del Land Art por ejemplo, se ha ido distanciando, cuyas corrientes postmodernas o neovanguardistas abren paso al llamado Informalismo y a un Arte Povera, que conlleva a una menor accesibilidad al entendimiento. Por contra, se percibe un acercamiento el arte llevado a la calle, es decir, proyectos públicos que aproximan el arte a la sociedad, o con iniciativas privadas desde pensadores y artistas. Este espacio público se reconvierte, donde hoy día la crítica explora en cualquier lugar y modo. Estas ganas de aplicar deseos comunes, a veces contraculturales en España, con unas vanguardias históricas que perduran, se aprecian cuando empiezan a surgir grupos a partir de 1948 como el "Dau al Set" en Barcelona y en menos de diez años en Madrid con "El Paso", dando pie a una riada de apariciones de grupos con inquietudes por todo el territorio nacional teniendo en Murcia al Grupo Puente Nuevo (surgido en 1960) y el Grupo Aunar (surgido en 1964) que aplican revulsivos actos, con pintores de la talla de Mariano Ballester a la cabeza en el primer grupo y con renovadores baluartes como Párraga y Aurelio en el segundo. Ofrecerán su arte en la misma calle, sobre todo en la plaza de la Cruz (Hernández Amores) de Murcia. Con ello se pierde esa idea elitista, donde sólo el ciudadano bien posicionado podía apostar por una obra de arte.

El término "obra de arte" está hoy más que nunca del todo abierto, también es consecuencia de las presiones que sufren constantemente los artistas para hacer algo nuevo, facilitado actualmente por la extensión abierta del término. "Y éste es un corolario, sobre todo, de la incapacidad para conocer el futuro histórico" (Danto, 1999: 207).

\section{Evolución histórica}

Nos podríamos remontar a civilizaciones más antiguas, pero, en este caso buscamos una base consolidada para iniciar los pilares de la crítica pudiéndola situar en la antigua Grecia, donde tratadistas, historiadores, o escritores de la prosa y poesía de moda como Policleto y Vitruvio recogen sus primeras nociones. La época grecolatina no interesa tanto como el siglo XX para nuestro trabajo pero es obvio que debemos hacer referencia a Platón con su teoría de las ideas (Ross, 2001) y Aristóteles, además de los famosos tratados de pintura y escultura de Xenócrates de Sicione.

El periodo del medievo tan oscuro en letras deja con lagunas esta historia en la que predominan los copistas y traductores por encima del resto. Llegaremos al Renacimiento y con él la entrada de la imprenta en Maguncia. A partir de ahora se incrementará el número de nombres que solamente recogeremos sin desentrañar en ningún momento sus profundas cuestiones y teorías, debido a que sería un trabajo algo desviado a nuestro propósito. Aunque como bien apuntaba Hermann Bauer "la crítica no 
debe ser confundida con aquellas Teorías del Arte expuestas, desde el Renacimiento, en tratados..." (Bauer, 1984: 40).

En Italia que es donde evoluciona con rapidez ese Quattrocento (S. XV) veremos como comienzan a florecer las historiografías como la de Antonio Tucci Manetti referida a Brunelleschi, o el mismo Lorenzo Ghiberti con Los Comentarios. Alcanzado el Cinquecento (S. XVI) tenemos a Giorgio Vasari con la célebre Vida de los mejores arquitectos, pintores y escultores italianos, origen del género biográfico.

Alcanzaremos las ideas de Alberti y Leonardo dentro no sólo de la crítica, también de la estética, que pueden considerase padres fundadores y representantes clásicos de la teoría de la pintura en el primer Renacimiento. Son Dante, Petrarca, Boccaccio o Cennini entre otros los que escriben sobre el arte toscano de su tiempo, dotándose de juicios artísticos, además de los que pasaron por Italia en esos momentos de esplendor como Alberto Durero, que aprendieron los secretos italianos.

Le seguirá en época barroca los italianos Giovanni Battista Agguchi, que observará más los estilos de los artistas en Bolonia, o aplicando los cánones grecorromanos a los de su momento como Giovanni Pietro Bellori, uno de los biógrafos más importantes de este siglo XVII.

El siglo XVIII deparará el que por muchos está reconocido como el primer crítico de arte moderno, Denis Diderot, cuyos comentarios se referían a las exposiciones realizadas en el París de la Ilustración, sobre todo los realizados en el Salón Carré del Louvre desde 1725. Publicó entre 1751 a 1772 la considerada como la obra más grande del siglo XVIII, La Enciclopedia.

Según Lionello Venturi antes del siglo XVIII las críticas de arte tuvieron que ubicarse en los tratados de arte y en las biografías de los artistas. En el siglo XVIII se escribe únicamente para plasmar la opinión individual sobre un determinado grupo de obras o de artistas (Venturi, 2004: 169). Una época donde le había precedido el empirismo sobre todo inglés con Francis Bacon, Hobbes, Locke, Berkeley o Hume en oposición al racionalismo continental con Descartes, Spinoza o Leibniz a la cabeza. Se alcanzan también los principios de Kant con su Razón Teórica y Práctica.

El crítico murciano Julián Pérez Páez, afirmaba que de hecho, la crítica de arte surge como tal para contrarrestar las carencias de la historiografía artística en un marco de especialización del conocimiento y cientificismo, es una urgencia por dar respuestas a nuestra modernidad, que hace proliferar los géneros como el epistolar o los libros de viajes, géneros que permiten mostrar las opiniones, las sensaciones de forma subjetiva y espontánea. En el siglo XVIII la literatura busca la expresión directa del sujeto, generando otra forma de escritura sobre arte, un género o subgénero literario, la crítica de arte.

Schopenhauer en su conciencia estética conserva reminiscencias de ideas expresadas anteriormente por Kant en su Crítica del juicio, pero Schopenhauer avanza en su estética contemplando la obra de arte ("el arte es la contemplación de las cosas con independencia del principio de la razón").

Seguiremos con el historiador alemán Johann Joacchim Winckelmann (Bauer, 1984: 41), considerado padre de la Historia del Arte y la Arqueología como ciencia moderna, donde aparecen entre otros el inglés John Ruskin. 
Y es con esta entrada del siglo XIX cuando se dará un paso adelante con todas las corrientes que irán apareciendo desde el positivismo con un gran representante como Auguste Comte creando la sociología como disciplina, creyendo que hay otras formas de hacer historia que la que existía sin adentrarse en religión o cultura (dentro del idealismo, la semiológica, o la historicista).

Dentro de la crítica romántica hemos citado a Baudelaire, quién realizará numerosos ensayos de las exposiciones llevadas a cabo en los Salones parisinos, considerando monstruoso el arte filosófico de tipo hegeliano, pues la pintura sugiere sentimientos y sueños, pero nunca razonamientos. De él pasaremos a la crítica realista donde destacan pintores como Delacroix, Courbet, Ingres, Millet, Daumier, o Corot. Y aquí tenemos a los más célebres de sus críticos T. Gautier y Charles Blanc.

Algunos continuadores de estas ramas en el siglo XX son Burckhardt, que prefiere una historia de los estilos, como la fenomenológica. Un aporte curioso, dentro de la condición de artista-escritor lo encontramos en el escultor Hildebrandt que escribió El problema de la forma en la pintura y la escultura. Otros como Heinrich Wölfflin, que en 1924 escribe Conceptos fundamentales en la Historia del Arte. Desmarcándose del formalismo tenemos a Rudolf Wittkower que se marcha para trabajar en el Instituto Warburg (1926), donde su fundador Aby Warburg partió de la biblioteca en 1909 con sede en la Universidad de Londres. Entre sus colaboradores tenemos a Ritz Saxl o Erwing Panofsky, junto con otro relevante, Ernst Gombrich, que seguirá la interdisciplinariedad del estudio de la obra, consiguiendo publicar su Historia del Arte en 1950 vendiendo millones de ejemplares hasta el día de hoy. Gombrich permanecerá en ese significado intrínseco de la interpretación iconológica de Panofsky, como Wittkower, buscando el conocimiento de otras materias auxiliares (lenguas clásicas, literatura, etnografía, psicología, etc.).

Por otro, un discípulo de Wölfflin primero y de Dvorak después, lo tenemos en Frederick Antal, y el profesor italiano Giulio Carlo Argan que como Venturi se mueven en una atmósfera marxista (Hauser, 1975). Enfoques sociológicos no faltarán como Arnold Hauser, u otros como Blunt, Francastel o el español Valeriano Bozal. Para ellos, como dice el historiador español Plazaola "el arte es producto de fuerzas sociales y origen de efectos sociales" (Plazaola, 2003: 122). Prosiguen la estela antropológica y cultural de positivismo de Taine en ese siglo XIX, analizando los aspectos socioeconómicos en los que se inserta el artista.

A finales del siglo XIX decía Oscar Wilde que había escrito ensayos como El crítico artista o El arte del ingenio, en una retórica sarcástica: “¿Críticos de verdad? ¡Ah, sería maravilloso! Estoy deseando que aparezcan. No nos vendría nada mal una escuela inaudible" (Wilde, 1997: 263).

También es cierto que el rechazo a la crítica, o más bien a los críticos siempre ha estado ahí, como cuando Tolstoi indicaba por el año 1880 que "por extraño que ello pueda parecer, los críticos han sido siempre hombres menos accesibles que los demás al contagio del arte. Son, por lo común, hábiles escritores, instruidos e inteligentes, pero cuya capacidad para ser emocionados por el arte está por completo pervertida o atrofiada. Y de esto viene que sus escritos han contribuido siempre y contribuyeron po- 
derosamente a pervertir el gusto del público que los lee y que se fía de ellos" (Tolstoi, 1998: 96).

El psicoanálisis también entrará en juego, aportando Freud y Jung sus teorías, 1legando a la teoría de la Gestalt con Rudolph Arnheim, hasta alcanzar a principios del XX la escuela austriaca de Graz y la de Berlín.

Clement Greenberg asevera que Occidente tiende hacia la autocrítica y que esta comenzó con Kant, a quien sutilmente clasifica como "el primer modernista real" porque fue el primero en "criticar el mismo significado de crítica". Y dice además que la esencia del modernismo radica en el uso de los métodos característicos de una disciplina para criticar la disciplina" (Danto, 1999: 85). Por tanto, según Arthur Danto, el modernismo es la edad de la autocrítica, tanto en forma de arte, de ciencia, filosofía, o moral. Le prosigue con reveladoras críticas, Umberto Eco, dentro de la semiótica cultural, continuado por William Morris, Michael Foucalt y Roland Barthes.

En esta riada de nombres debemos nombrar la Escuela de Frankfurt con su representante más destacado en la figura de Theodor Adorno, seguido por ejemplo de más filósofos como Walter Benjamin cuyo ensayo de 1936 La obra de arte en la época de su reproductibilidad técnica, critica esa reproducción técnica de la obra de arte que hace que se atrofie el aura de la misma.

La crítica actual pasa a estar vinculada al periodismo, portavoces del gusto de artistas coetáneos. Decía Umbral en un artículo (El Mundo, 21 de octubre de 2000) que el maestro Fernando Lázaro Carreter acuñó o difundió la expresión "prosa de arte" para definir la de Valle-Inclán, Gabriel Miró y otros. El periodismo de arte es el que se viene haciendo en algunas columnas periodísticas. Ejemplos como Carmen Rigalt, Maruja Torres, Carmen Rico-Godoy, Rosa Montero, Manuel Vicent, Vicente Verdú, Raúl del Pozo, Eduardo Haro-Tecglen, Gabriel Albiac, Manuel Hidalgo, Antonio Burgos, Baltasar Porcel, Vázquez Montalbán, Cándido, Campmany, etc.

El periodismo de arte se pone al servicio de la actualidad, o la crea, con todos los atributos de la información, pero con una prosa subjetiva, lo que implica también un pensamiento subjetivo y libre, que viene a indagar sobre la obra, aportando por momentos, los mejores hallazgos literarios en prensa.

Afirmaba Eduardo Collado en su blog (www.eduangi.com) en 2010 "no quiero un periódico para reafirmar lo que pienso, quiero un periódico que me haga reflexionar, que me estimule mental e intelectualmente, que me haga sentir lo que leo, que me de proximidad y todo eso con belleza. El periodismo no es sólo información, es arte, es placer, a fin de cuentas, un excelente producto con un valor incalculable y eso salvará el periodismo, hará que la gente vuelva a comprar periódicos, y como dijo una persona el otro día en un evento, hará que los periodistas puedan hacer mejor el Mundo".

Desde una visión nacional, podemos comenzar por el catalán Eugenio d'Ors (Ureña, 1982: 40), impulsor del movimiento conocido como Novecentismo, se formó en los ambientes literarios modernistas y cuya actividad periodística se fue haciendo cada vez más famosa con sus pseudónimos en revistas literarias de la época. Otro pionero español de la crítica, prácticamente de la generación del anterior, es Ortega y Gasset que publicó Sobre la Crítica de Arte en 1925 y recogía que "en otro tiempo podía el crítico comportarse simplemente como un juez: partiendo de un código pre- 
establecido, sentenciar sobre el hecho concreto. Ese código preexistente acaparaba sus resoluciones y cobijaba su criterio. Pero el arte de nuestro tiempo, desde el fin del impresionismo en pintura y del simbolismo en poesía, carece de códigos sancionados. El crítico tiene que operar a la intemperie y a campo traviesa; al mismo tiempo que juzga una obra tiene que conquistar autoridad para la ley general que aplica" (Ortega y Gasset, 2005: 195). Ortega y Gasset, muy sabio, reconoció sarcásticamente que se unía al arte nuevo de jóvenes creadores, porque cabían dos cosas para estos jóvenes emergentes, o fusilarlos o esforzarse en comprenderlos, y él optó por esto último.

Continuarán otras generaciones destacando entre ellos Juan A. Gaya Nuño, culminando su trayectoria con la obra Historia de la Crítica de Arte en España en 1975. Después vendrán otros grandes nombres como Camón Aznar, Julián Gallego, Juan A. Ramírez, Gonzalo Borrás, Jaime Brihuega, y muchos más (Guash, 2007).

La historia nos demuestra que este primer cuarto de siglo XX existía un alto índice de analfabetismo, y muchas publicaciones tenían una corta vida y la prensa solía ser una pequeña empresa frente a lo que iba a ser más adelante (Pizarroso Quintero, 2010: 46). En 1919 se constituyó el primer Sindicato Español de Periodistas adherido a UGT y presidido por Ezequiel Eudériz, redactor de El Liberal.

Ha habido personalidades que han transformado y mejorado su devenir, como la creación del primer trust o conjunto de prensa, coordinando varios diarios como $\mathrm{El} \mathrm{Li}$ beral, El Imparcial, El Heraldo y más tarde El Sol, gracias a Miguel Moyá, periodista y diputado, siendo el primer presidente de la Asociación de la Prensa en Madrid creada en 1895. Avanzados unos años el siglo XX surgen infinidad de diarios cuyos nombres no pueden recogerse en este estudio. Al igual que destacadas figuras como Torcuato Luca de Tena que fundó el semanario Blanco y Negro en 1891 perteneciente a Prensa Española, junto con Álvarez Ossorio. Respecto a revistas de humanidades, arte y cultura españolas desde el Archivo Español de Arte en 1925, surgirán un buen número después de la Guerra Civil como Goya, Revista de Ideas Estéticas, Traza y $B a z a$, etc., entre otros cuadernos. Alcanza popularidad internacional la surgida a raíz de la exposición surrealista de 1937 en Tenerife, Gaceta de Arte.

Muchos historiadores españoles de renombre hasta bien entrado el tercer cuarto de siglo XX han caminado por el terreno de la arqueología, el patrimonio y la historia de España como Antonio Blanco Freijeiro, el cartagenero que fue director del Museo del Prado Alfonso Emilio Pérez Sánchez, o Joaquín Yarza Luaces, continuando en esa estela de no acercarse a planteamientos contemporáneos con un perfil puramente de "historiadores", por lo que un masivo grupo de especialistas se han quedado obsoletos o han preferido no dar el paso de adentrarse al difícil terreno de lo contemporáneo, donde prefieren la mirada del pasado más que la de sus complejos e inaccesibles coetáneos que están marcando el devenir de nuestro arte.

En España comienza a irrumpir una crítica o valoración del arte contemporáneo a partir de una avanzada mitad del siglo, con figuras como Valeriano Bozal, que escribe y recoge nuestra vanguardia española del surrealismo, el cubismo, etc; el filósofo Eduardo Subirats, Santiago Amón, la historiadora Lourdes Cirlot que ofrece todo un estudio del ámbito catalán, o el filósofo murciano Francisco Jarauta, entre otros. Figuras nacidas entre los 40 o 50 del pasado siglo, inclinadas hacia esa vertiente de es- 
cribir sobre lo que acontece en su tiempo. Pensadores de hoy que ofrecen algunas reflexiones frescas con puntos de vista diferentes, donde se encamina el verdadero crítico, hacia la interdisciplinariedad, asociando diferentes materias en ámbitos múltiples que abarcan desde la historia del arte, el periodismo, la antropología, la filosofía, la geografía, etc.

Desde hace algo más de una década existen infinidad de revistas, blogs, Web, etc., así como revistas de Bienales e internacionales como October que surge en 1976 con Rosalind Krauss al frente, y un mayor número en las décadas siguientes, incrementándose exponencialmente el medio Internet, como la revista Descubrir el Arte surgida en 1999, una de las más interesantes respecto a manifestaciones artísticas y épocas tratadas en España, donde colaboran o pertenecen al Comité Asesor figuras españolas como Fernando Castro Flórez, Fernando Checa, Kosme Barañano, o el murciano Cristóbal Belda.

\section{La crítica y el crítico}

La valoración crítica habitualmente ofrece, desde el punto de vista estético y formal, un estudio contextualizado y subjetivo, cuya identidad refleja una evidente personalidad marcada en el lenguaje. En otras, el supuesto crítico simplemente informa, o valora apoyado en comparaciones, o asume fuentes contrastadas y datos precisos con una neutralidad basada en un análisis académico.

Ellos tienen un poder de arrastre, es decir, pueden a través de sus medios desbancar, hundir o situar en lo más alto la obra del artista. En sus palabras quedan feroces ataques, bellas adjetivaciones o controvertidas afirmaciones, enrevesados circunloquios para no pronunciarse, o sin más, formalismos de retóricas y densas frases de poco calado para el público general al que va destinado.

Como decía Baudelaire debe afrontar una visión exclusiva de verdadera pasión que abra el enfoque de los que puedan contemplar la obra sometida a análisis.

Obtenemos en este particular universo afamados escritores, artistas, historiadores del arte, o los mismos periodistas con inclinación vocacional. En referencia a esta última profesión, el área de la comunicación o el periodismo establecerá sus pilares en la II ${ }^{\mathrm{a}}$ Mitad del XX, donde podemos hacer referencia al austriaco Paul Watzlawick (1981) con la publicación de sus teorías de la comunicación humana, aplicando sus axiomas, germen del constructivismo basándose en el pensamiento de Kant, Descartes, Hume o Berkeley.

La influencia crítica en el ámbito cultural es extensa frente a cualquier otra disciplina, es decir, un ciudadano está más sensibilizado con el aspecto u actividades socioculturales que se desarrollan en su entorno geográfico que de otros campos o aspectos, aplicando el público su propia crítica personal, por lo que en alguna ocasión se ha afirmado popularmente que todos somos consejeros de Cultura, así como se suele decir popularmente que todos somos seleccionadores de fútbol, ya que donde quiera que vaya ese aspecto artístico-cultural afectará a la sociedad de alguna u otra forma. A veces por la implicación del arte en el terreno urbano, otras en salas públicas, reflejado también en los medios, en notas de actualidad, en constantes agendas de eventos, incluso desde agencias de publicidad que saben como atraer la atención a un público que está ahí. Un diálogo o juego urbano de la cultura como sucedió en Mur- 
cia en la bienal de arte conocida como PAC (Proyecto de Arte Contemporáneo) o el Festival Alter-Arte donde entremezclaban en el espacio artista-arte-público y en ocasiones llegaba a interactuar fuertemente el viandante con las instalaciones generadas. Al fin y al cabo cierto arte contemporáneo hace partícipe a la sociedad que se pregunta e interroga dando pie al surgimiento de una crítica popular o autocrítica de lo que observa. La ciudad como un medio de comunicación más (Parreño, 2006: 66). El arte es irremediablemente desde siglos una pieza en la estructura humana que contribuye a todo tipo de teorías populares, especulaciones, sarcasmos y contradicciones que siempre han estado y estarán.

Según nos indicaba Suzi Gablik, "la función que hoy tiene la crítica en mi opinión, consiste en reconstruir enteramente las premisas fundamentales de nuestra cultura; tiene la obligación de desafiar las suposiciones sofocantes de nuestra mentalidad occidental secular y tecnócrata. No se trata únicamente de ver las cosas de otra manera, sino de ver otras cosas" (Gablik, 1987: 120).

"En la historia del arte encarnan valores, distintos según la época, el gusto, o incluso la moda" (Pérez Carreño, 1999: 329). Valores que nos hacen preferir unos artistas sobre otros, aceptados por un consenso que sin embargo cambia y es revisable.

Se ha dicho alguna vez que la esencia y gracia del ser humano es su imperfección, pero si tuviéramos que elegir un crítico ideal, Danto lo preferiría así cuando dice que sería delicado, experimentado, abierto, capaz de comparar, y por ello posee un conocimiento muy amplio del arte y está dotado de buen sentido: "El conjunto de los veredictos de éstos, donde quiera que se encuentren, es el verdadero patrón del gusto y la belleza" (Danto, 1999: 124). Por el contrario, el que no tiene delicadeza, bajo la influencia del prejuicio y faltando el buen sentido, no estará calificado para discernir las bellezas del diseño y el razonamiento...

No obstante, como dice Moxey (2004: 122), "la determinación psicológica e ideológica no puede evitar que un autor o autora dote a sus relatos históricos de una persuasión política que se ocupe de los acuciantes temas sociales y culturales de su época". Y continúa diciendo que la subjetividad del historiador no sólo está parcialmente determinada por fuerzas inconscientes, sino también por las tradiciones ideológicas características de su situación en la historia.

Al igual que la pintura, a la escritura le ha costado siglos ser autónoma, independizarse de un contexto. En el análisis de crítica artística debería encauzarse en una cierta imparcialidad, pero nadie puede desligarse de su ser y permanecer ajeno a lo que acontece. Oscar Wilde estaba en esta sintonía de expresar abiertamente sus opiniones, afirmaba que el crítico es el que puede traducir de un modo distinto o con un nuevo procedimiento su impresión ante las cosas bellas, y reconocía que "la crítica deja de serlo en cuanto ejerce alguna influencia. El objetivo del verdadero crítico consiste en intentar expresar sus distintos estados de ánimo, no en tratar de corregir las obras maestras de los demás" (Wilde, 1997: 263). Pero, por ejemplo, Rainer Mª Rilke nos aconsejaba que leyéramos lo menos que pudiéramos de cosas estético-críticas ya que "o son opiniones partidistas, petrificadas y vaciadas de sentido en su endurecimiento contra la vida, o son hábiles juegos de palabras, en que hoy se saca una opinión y mañana la opuesta. Las obras de arte son de una infinita soledad, y con nada 
se pueden alcanzar menos que con la crítica. Sólo el amor puede captarlas y retenerlas, y sólo él puede tener razón frente a ellas" (Rilke, 2006: 37).

Para ser crítico hay que tener infinitamente más cultura que para crear, decía Oscar Wilde, y esta característica es necesaria, disponiendo de unos recursos que si se acompañan de ingenio se convierte el crítico en creador.

El mundo literario debe estar en el pensamiento del crítico, puede utilizarse como referente, algo que decía el murciano Miguel Ángel Hernández cuando afirmaba que "la crítica de arte se ha abierto al mundo de las ideas, al giro lingüístico, cultural, antropológico... y debe hacerlo también al giro lingüístico. El crítico debe conocer también el universo literario como una caja de herramientas para poder afrontar el hecho artístico" (Hernández-Navarro, 2006: 283). A la vez que debemos clasificar o identificar clases de críticas o formas de hacerla porque nada tiene que ver la crítica de un diario, con la de una revista especializada de investigación o la introducción a un Catálogo.

El artista contemporáneo debido a varios factores necesita en ciertos casos explicar su obra, aunque también lo vemos ejercer de crítico o comisario. Como dijo Pedro A. Cruz Fernández "el artista deviene en crítico y el crítico convierte su trabajo en arte de la palabra (literatura que deviene de la imagen), con lo cual se produce una confluencia que salva a ambas manifestaciones del agotamiento y, a la vez, les permite mantener su independencia pese a la estrecha ligazón existente entre ellas" (Cruz Fernández, 2006: 21).

Son muchas las coincidencias de que en la posmodernidad la historia del arte debe tener una función pedagógica y desde enfoques multidisciplinares. Que ante la globalización debe también dirigirse a aquellos públicos que necesitan sentir, vivir y comprender el arte (Guash, 2007: 33).

\section{Panorama murciano}

El campo de la crítica a través de la prensa en la ciudad de Murcia nos conduce a más de un siglo de historia con numerosos diarios surgidos y desaparecidos, unos con más duración que otros. Los que han pervivido han sabido soportar momentos delicados y sobreponerse constantemente, y de alguna forma reinventándose con continuas ofertas e ideas, hasta incluso cambiando su formato o nombre.

La Región se encuentra históricamente avanzada a su tiempo respecto a otras regiones, ya que sobre 1706 se conoce la existencia del diario de La Gaceta. Irrumpen diversidad de diarios a inicios de siglo XX, pero destacamos Correo de Levante fundado en 1899, otros de ideología religiosa, de ahí nació La Verdad en 1903, el único superviviente de todos sus contemporáneos en este momento. Le seguirá El Tiempo en 1908, El Levante Agrario en 1915, y El Liberal, aparecido en 1902 que cambió de nombre por Línea hasta el año 1983 (Crespo, 2006).

José Martínez Tornel considerado padre de la prensa murciana, ocupó el cargo de Presidente de la primera Asociación de la Prensa, y fundó en 1879 el Diario de Murcia hasta 1903, teniendo un año duro de competencia con el nuevo El Liberal del cual pasaría a ser redactor.

En un gran salto, destacamos la aparición en 1988 de La Opinión cobijada bajo el Grupo Editorial Prensa Ibérica al que pertenece, y en 1990 del Diario 16, que perte- 
necía al Grupo 16 hasta 1998 y que pasó al Grupo Voz con el que desapareció en 2001, siendo de distribución nacional y con ediciones regionales y locales.

Por otro, la Asociación de la Prensa en Murcia se originó allá por el año 1906, manteniendo una historia periodística paralela a la que ha acontecido en Murcia durante más de un siglo. Su mantenimiento es fruto de sus asociados, que rondan alrededor de doscientos periodistas. Apoyan las artes murcianas y conceden los Premios Laureles. Han publicado diversos semanarios o Anuarios. Pero destaca por encima de estos La Hoja del Lunes que apareció en 1943 con la rotativa a través de La Verdad, perdurando hasta 1988.

No podemos entrar en todas las publicaciones que se fueron realizando en el siglo $\mathrm{XX}$, pero dentro de las publicaciones culturales, hay que detenerse en la aparición de Verso y Prosa en 1927 colaborando los mejores escritores de entonces, desde Jorge Guillén, Alberti, Cernuda, Gerardo Diego, Dámaso Alonso, Lorca, Aleixandre, marcando un hito en la prensa cultural murciana. Destaca otra como la editada por la Academia Alfonso X el Sabio llamada Murgetana desde 1949, y otras como Monteagudo, vinculada a la Universidad como posteriormente muchas, etc.

Aparece a escena un diario nuevo para competir con La Verdad y La Opinión, llamado El Faro, creado en 2002, bajo la dirección de Manuel Ponce, que empezará a tambalearse desde 2010 hasta desaparecer. Y con él algún periódico gratuito, boom que comienza en 2004 y que ha acompañado las calles de Murcia en los últimos años como Nueva Linea, Qué!, Crónica del Sureste, 20 Minutos, Vecinos, Mercado, etc.

Actualmente en La Verdad, en su edición del Semanario de Literatura, Artes y Ciencias (Ababol), representa como decía su director José María Esteban Ibañez hasta 2009 una saludable excepción cuyo mantenimiento es labor de artistas y de periodistas acompañando la labor diaria de lo que acontece en asuntos puramente artísticos, musicales, teatrales, cineastas, y demás ámbitos culturales, en nuestra tierra murciana.

Hoy día la ciudad de Murcia, gracias al Cendeac (Centro de Documentación y Estudios Avanzados de Arte), punto de encuentro internacional debido al fenómeno global, que reúne congresos, seminarios, conferencias, y presentación de libros entre otras cosas, al que acuden personalidades importantes del área de la crítica de arte, ha hecho en parte que esa carencia se disipe y que el público pueda obtener la riqueza y amplia visión que ofrece, acercándonos a otros pensamientos de forma directa. Un centro pionero en el que estuvo al frente en su origen el actual Consejero de Cultura Pedro Alberto Cruz por el que pasó después Miguel Ángel Hernández, seguido de Yaiza Hernández, hasta llegar Javier Fuentes.

Murcia ofrece otros lugares de encuentro e interés donde la crítica de arte puede estar presente, abarcando desde sedes institucionales que ofrecen exposiciones temporales, junto con las Galerías de Arte, donde se producen altibajos constantes, abriendo y cerrando en cortos periodos.

Desde escritores murcianos nos hemos adentrado en una crítica artística que en muchas ocasiones se aleja de la definición propiamente dicha, pero sí que pervive en ocasiones el legado histórico, la documentación rigurosa de la investigación del periodista o de historiador al servicio de la prensa, y todo ello con infinidad de colaboradores que probablemente queden fuera de este apartado. Por ello, hemos intentando 
seleccionar a los que hemos creído significativos, que trataron o siguen tratando esa cultura artística del momento. Un contraste de autores, que han forjado los niveles en los que se encuentra la crítica de arte periodística actual en Murcia. Y hacen posible en la prensa que salgan a la luz exposiciones en mayor medida sin crítica, o con críticas más bien livianas.

De la mano de Pedro Alberto Cruz Fernández, y por "falta de relatos generales [...] y la necesidad de su estudio y compilación para poder entender la evolución del arte en el siglo pasado" (Cruz Fernández, La Verdad, 8 de diciembre de 2012), decidió recoger una serie de doce artículos en el Semanario Ababol de La Verdad todos los sábados con el título La Crítica de Arte en Murcia, que comenzaron en diciembre de 2012, en los que hablaba de esos críticos de arte en la prensa murciana.

Murcia tiene unos cimientos fuertes en el campo literario-cultural, con la denominada "promoción de Azarbe" con Francisco Cano Pato, Jaime Campmany, Castillo-Elejabeytia, Salvador Jiménez, Antonio Oliver, Andrés Sobejano, cuyo padre fue el pintor costumbrista José Ma Sobejano, su hijo Gonzalo Sobejano o Juan García Abellán.

Próximos a esta generación encontramos a la figura de Luis Gil de Vicario, que aunque no era murciano, se dedicó en parte a la crítica, además de sus facetas de pintor, escritor e ilustrador gráfico. Una trayectoria de pintor-escritor en prensa que continuarán otros como Asensio Sáez, Muñoz Barberán, Enrique Nieto, Juan Bautista Sanz, etc.

Otra figura destacada sería Raimundo de los Reyes creando la Revista Sudeste junto con José Ballester y Antonio Oliver, en el momento convulso del grupo de la Generación del 27. Otros como F. Díez de Revenga o Dictinio de Castillo-Elejabeytia, interviniendo este último en la revista Azarbe (1946-1948) y Tránsito (1979-1982). De Antonio Oliver podemos saber mucho más en el museo que lleva su nombre, junto a su mujer Carmen Conde en Cartagena. Escribió el ya famoso libro Medio siglo de Artistas Murcianos (1900-1950), Escultores, pintores, músicos y arquitectos.

Otros como Francisco Alemán Sáinz, quien recogió una gran amplitud de géneros, destacó aquí con sus Ensayos Murcianos, o José Luis Castillo Puche perseguido por la censura y que el crítico José Belmonte Serrano le dedicó un libro(Belmonte Serrano, J. 2000). Por ejemplo, Francisco Alemán Sáinz destacó en la publicación Monteagudo, nacida en 1953 al amparo de la Universidad. Por sus manos pasaron todos los artistas que realizaban alguna exposición por Murcia.

Desde que comenzó allá por los años 50, Antonio Pérez Crespo defendió los intereses murcianos, y acabó como Cronista Oficial de Murcia. Continuamos con Antonio Segado del Olmo, uno de los más completos, truncándose la que podría haber sido una larga carrera, quien falleció con 43 años en 1987, dejando el legado de estudios de artistas, como el que encontramos en 7 pintores con Murcia al fondo, sin contar con sus particulares novelas.

Otros escritores que han recogido escritos del arte murciano más que interesantes son el ciezano Antonio de Hoyos, quien sacaba a la luz el libro del pintor Carpe entre otros, y cuyas ilustraciones de sus poemarios por ejemplo estaban realizadas por los buenos pintores de aquel entonces, como les sucedía a otros escritores como Cano Pato, Antonio López Baena, etc. 
Un puesto honorable lo ocupa José Ballester, quien fue director de La Verdad en dos ocasiones y presidente de la Asociación de la Prensa. Uno de sus célebres libros Otoño en la ciudad recuerda a la trilogía que vendría de Francisco J. Flores Arroyuelo, con connotaciones evocadoras a la tierra murciana. José Ballester "clave para la comprensión de todo el movimiento cultural-literario y artístico, fundamentalmente- producido en el primer tercio del siglo pasado en nuestra Región" (Cruz Fernández, $L a$ Verdad, 9 de febrero de 2013).

Continuamos con muchos más como Cayetano Molina que trabajó en Línea, al igual que José Sánchez Moreno, y Manuel Jorge Aragonenes (Saura Mira, 1998: 4142), que pasó a la historia de la pintura en Murcia gracias a su investigación mural. Llegaría el turno del pintor, profesor y colaborador habitual en La Verdad Antonio Díaz Bautista, que derivó en los últimos años a los artículos musicales en prensa. También, el ilustre Cronista de la ciudad e Hijo Adoptivo de Murcia, entre otras méritos y ocupaciones, Carlos Valcárcel Mavor periodista de La Hoja del Lunes, fallecido a mediados de 2010, sin lugar a dudas referencia de las costumbres y tradiciones murcianas, claro investigador en donde apreciamos a otros que siguen esos pasos como Pedro Soler o Antonio Parra. Este último, reconocido como uno de los gestores flamencos más destacados de la Región, en el que también hay cabida a la labor de investigador como el libro Abenarabi, dedicado al gran místico andalusí del siglo XII que vivió en Murcia y de quién reconoce ser más reconocido fuera que en tierras murcianas, algo que le sucede a muchos de los artistas de nuestra tierra, que no son profetas en ella, pero sí que han sido valorados fuera.

Seguimos mencionando personalidades de la cultura murciana como Martín Páez, comisario y responsable de tantas exposiciones. Con él comenzaron el galerista Emilio Morales, y la consolidada Nieves Fernández que acabó después de la Galería Yerba, montando su propia Galería en Madrid. Hermano del galerista Emilio Morales, sería el desaparecido historiador José Luis Morales, una de las personalidades en el terreno literario-cultural más prometedoras que tuvo Murcia, como el texto que le hizo a la pintora $\mathrm{M}^{\mathrm{a}}$ Dolores Andreo en 1996, al igual, por ejemplo, que el brindado por el escritor Pedro Olivares Galván a Mariano Ballester (Crespo, 2007: 105-126).

Otros, como el periodista Salvador Jiménez dentro de los escritores de posguerra murcianos, tendrá muchas veces palabras interesantes sobre el arte contemporáneo murciano que le toca vivir.

Pedro García Montalvo también dejará su firma en La Verdad, escritor de varios volúmenes de cuentos y de novelas, considerado por Pascual Vera como "uno de los más firmes valores de la narrativa murciana actual". Continuamos con el que sin duda es uno de los grandes defensores y conocedores de la pintura murciana que le ha tocado vivir, Antonio García Berrio quién escribió sobre pintores como Aurelio. Otros como Ramón Ferrando que ejerce ahora en Levante-EMV, quien obtuvo en 2011 el premio "Libertad de Expresión de la Unión de Periodistas Valencianos" (Martínez, M., La Verdad, 4 de mayo de 2008). Antonio Martínez Cerezo, quien ofrece ese canto de amor por su tierra en sus libros, así como Tomás Salvador, Arturo Andreu, Antonio Corral Castañeda, Alfredo Aracil o Patricio Peñalver. También colaborador de La Verdad como crítico literario lo ha sido el profesor de la UM José Belmonte Serrano quién 
últimamente comisaría exposiciones. Otro buen periodista es Pedro Soler, inconmensurable en La Verdad, sobre todo los sábados con su edición Ababol. Logró en 2009 la insignia de oro entregada por la Asociación Murciana de Críticos de Arte (AMUCA), reconociéndole como maestro del periodismo cultural, gracias a la labor de investigador y experiencia, fiel reflejo del periodismo documentado.

Pedro Alberto Cruz Fernández lleva una dilatada carrera apostando por críticas en prensa, participando en libros, exposiciones o conferencias. Formó parte del cargo de presidente durante un tiempo de AMUCA, pasando a manos de José Alberto Bernardeau en 2010, colaborador en la prensa murciana, el cual publicó en 2009 su Tesis Doctoral titulada Prensa y Arte en Murcia. 1970-2000.

El actual Consejero de Turismo y Cultura en Murcia Pedro Alberto Cruz Sánchez prosigue los pasos del padre, escribiendo en ocasiones artículos además de haber publicado libros, participado en catálogos y habitual conferenciante, etc.

Más recientes: un excelente crítico de arte que pasó por nuestra prensa fue Pedro Medina, conferenciante de aspectos actuales del arte, pasando por La Opinión acabó por instalarse en Madrid, y a esos pasos le seguirá Mara Mira que por un corto periodo de tiempo trabajará en el mismo periódico, exdirectora del Centro Párraga de Murcia, ahora trasladada a un ámbito profesional fuera de Murcia escribiendo en El País. Antonio Arco se centra más en la literatura y temas culturales diversos. Y Julián Pérez Páez ha colaborado en alguna ocasión en escritos de arte.

Jóvenes todavía en este terreno son Pepa García en La Verdad por un lado, y Ana Guardiola y Julia Albaladejo en La Opinión por otro, cuya labor desempeñada de todas ellas suele ser de mera información objetiva y plural, sin el aporte de una riqueza crítica, junto a nuevos colaboradores esporádicos como Nacho Ruiz de la Galería T-20, etc.

Existen autores del nivel de Francisco Jarauta reconocido a nivel internacional, a caballo en la actualidad entre diversas ciudades como Berlín y Murcia, participativo constante en seminarios, marca un hito para nuestra crítica en Murcia. Su expansión con el consiguiente "exilio" ha dejado lastrada en parte a la crítica murciana, siendo hombre de ideales universales. Remarco con esto esa idea que recogemos en un foro de globalización, en cuya conferencia celebrada en diciembre de 2004 decía: "Pero la globalización no sólo debe ser entendida como el conjunto de procesos económicos, científicos y tecnológicos que, en su articulación, transforman y define el nuevo orden del mundo. Tras ellos operan complejos mecanismos mediáticos cuyo alcance transciende el hecho mismo de la comunicación" (Jarauta, 2005: 9). Con esta declaración, Jarauta intenta dar una visión adelantada, antes de que Facebook o Twitter dos años después comenzaran, fenómenos de la cultura al alcance de todos, con cuya revolución tecnológica alcanzamos otros niveles de desarrollo, conocimiento, exportación, universalización, etc.

Con esto se quiere alcanzar ese principio de interconexión a través de las redes sociales, sin olvidar los blogs ya más relegados, y superados por los primeros. La vía online de cualquier medio es una realidad y el soporte irá modificándose, pero lo que no podrá cambiar será la necesidad del mercado cuya sociedad podrá estar ahí, informando, opinando o valorando ese nuevo proyecto, instalación u obra de arte. 


\section{Valoración}

Decía Hegel, hablando de sus tres momentos de Espíritu Absoluto, que son arte, filosofía y religión (los tres, según A. Danto, esenciales transformaciones de uno en otro), y comparable con Oteiza (1994: 76), que existen tres caminos de salvación espiritual. $\mathrm{Y}$ estos deben estar presentes cuando analizamos a un artista, ya que su idiosincrasia depende de cómo desentraña y actúa el crítico casi como un psicólogo de la obra de arte hecha.

Desde hace algo más de una década el periódico impreso se ha visto sometido a una nueva corriente o medio de comunicación, el periodismo digital o ciberperiodismo. Aunque este fenómeno ha llevado al nacimiento de publicaciones únicamente digitales que optan por no disponer una versión en papel, ya que los costes de impresión y producción se incrementan y su difusión es mucho más extensa y eficaz.

Es una nueva forma de hacer noticias desarrollando un lenguaje propio y específico, que se queda a medio camino entre el lenguaje tradicional escrito y el lenguaje audiovisual. Esto se debe a que la red permite la inclusión de texto, sonido e imágenes facilitando al usuario la lectura y comprensión de la noticia. Un lenguaje no tan formal como en la prensa tradicional, ya que la rapidez también es una característica propia de este medio, tanto en la lectura como en la edición de la información.

Es cierto que en la versión digital la actualización se hace prácticamente en tiempo real, de modo que el periódico, como el lector, siempre está informado de todo lo que acontece. Desbanca incluso a la TV en rapidez.

Facilita la interacción entre emisor y receptor. Existen blogs con zonas de comentarios con críticas y opiniones de usuarios. Esto mejora el trabajo del periodista que se cerciora que su mensaje o información tiene repercusión y al mismo tiempo, puede subsanar sus errores de redacción (recordando que el lenguaje empleado por el periodista está más cercano al oral que al escrito propiamente dicho, aunque mantenga ciertas normas lingüísticas). Además de una nueva concepción del receptor más allá de considerarse un mero consumidor de información, surge el llamado periodismo ciudadano donde la acción de los mismos toma un papel protagonista en la redacción de noticias.

Aunque el encanto y sabor de la prensa escrita, en cambio, atrae a los amantes de la escritura, en un lenguaje bien empleado y riqueza léxica que nos hace pensar que la crítica de arte pervivirá en formato en papel.

Respecto al análisis de textos actuales de los dos periódicos hegemónicos en Murcia, La Verdad y La Opinión, comprobamos como ciertas noticias guardan semejanzas entre ambas, coincidiendo en el tiempo. Noticias simultáneas e idénticas, cuyas coincidencias resultantes son debido al reducido ámbito en el que se mueven.

Se deduce que algo habitual en nuestros diarios son esos recursos de la "entrevista" que no se pueden considerar crítica. Observamos muchas entrevistas in situ, labor de buenos periodistas, acudiendo al lugar y obteniendo información de primera mano, pero dejan de lado una auténtica crítica de lo que acontece en nuestra cultura, si exceptuamos ciertos casos, existiendo una liviana crítica. Se realiza una labor informativa bien documentada, con excelentes fuentes de la noticia, pero como sucede en muchos periodistas, es acompañada de una olvidada crítica cuyas citas le allanan el terreno. 
La mayoría de ocasiones acaban en información objetiva e imparcial, mera noticia del acontecimiento, sin una verdadera crítica, esencia para la comprensión de cómo emplean los valores de enjuiciamiento y éticos al profundizar en este aspecto de las artes en tierras murcianas. Hay que tener en cuenta que la mayoría de los acontecimientos artísticos locales poseen una prensa de igual forma cercana a este propio universo cultural murciano. Y por otro, la conjunción artistas-periodistas suelen tener cierto vínculo de amistad.

Aunque fuera de nuestro propósito destacamos la buena intervención aparecida en la Crítica Musical (en este caso música popular), a cargo de Jam Albarracín (La Ver$d a d)$, algo no tan habitual en artes plásticas. Lo mismo sucedía en los conocidos artículos de los "Lunes de Música" del tristemente desaparecido Antonio Díaz Bautista, con su conocida Ficha Discográfica, y por otro, con Ángel H. Sopena en La Opinión.

Con la documentación analizada en esta prensa local, debemos incidir que en $\mathrm{La}$ Verdad, Pedro Soler con el formidable Semanario Ababol y Pedro A. Cruz Fernández, son los críticos más destacados de este análisis. Éste último, es uno de los maestros de la crítica en Murcia en la actualidad, con inicios embaucadores, reflexivos y tintes filosóficos, en ese lenguaje culto pero entendible del que suele hacer gala, nada farragoso de lo que a veces presenta su hijo Pedro A. Cruz Sánchez.

Pedro Soler, un baluarte de la cultura en La Verdad, será menos lírico que el anterior y ofrece un bagaje de experiencia que se deja sentir al momento. Entrelaza muchas citas y convierte en datos muchos recuerdos anteriores. Gracias a su impecable labor avalada de años, el público ha tenido una mayor y detenida información de lo que sucedía y continúa sucediendo.

Murcia en el último INE se situaba en el ranking como séptima ciudad más poblada de España, un puesto que debería hacer honor también en su prensa escrita, ya que ha poseído una tradición artística brutal, desde la Generación del 20 (Gaya, Gómez Cano, Joaquín, Bonafé, Garay, Almela Costa, Flores, etc.), pasando por el prolífico fenómeno de artistas de Posguerra como Aurelio, Carpe, Avellaneda, Muñoz Barberán, Molina Sánchez, Párraga, Hernansaéz, Ma Dolores Andreo, Medina Bardón, etc.; de los que recogía buena cuenta de ello en mi Tesis Doctoral El paisaje en la pintura murciana en la segunda mitad del siglo $X X$, alcanzando el periodo a caballo del XX al XXI con diversidad de líneas vanguardistas, con buscadores incesantes, artistas emergentes que son portadores de una indudable posición de calidad y puesta en valor, que debería ser paralela en cuanto a crítica de arte producida respecto a las obras de arte que aterrizan en suelo murciano. Y como los escasos "Pedros" (Soler y Cruz), debemos apoyar e insistir en ofrecer una crítica mayor que nos remita a la reflexión, al planteamiento, al pensamiento e interrogación, y podamos disfrutar no sólo de la comunicación informativa de las exposiciones, sino, también, que vaya acompañada de una crítica que nos haga más grandes y más humanos, mostrando nuestro raciocinio e intelecto en algo que continúa avanzando como es el arte.

\section{Referencias bibliográficas}

ARCHIVO MUNICIPAL DE MURCIA (2003): El papel de nuestra historia. Murcia, Consejería de Educación y Cultura. Colabora: Fundación Cajamurcia. 
BARASCH, Moshe (1999): Teorías del Arte. De Platón a Winckelmann. Madrid, Alianza Editorial.

BAUER, Hermann (1984): Historiografia del arte: introducción crítica al estudio de la historia del arte. Madrid, Taurus.

BELMONTE SERRANO, José (2000): Visiones y apariciones de un escritor: José Luis Castillo-Puche. Murcia, Nausica, Edición Electrónica.

BORRÁS GUALIS, Gonzalo M. (1996): Teoría del Arte I, Historia 16.

CRESPO, Antonio (2007): "Escritores Murcianos en la Penumbra". Murgetana, Murcia, pp. 105-126.

CRESPO, Antonio (2006): III Centenario, Prensa en Murcia, 1706-2006. Murcia: Región de Murcia, Consejería de Educación y Cultura.

CRUZ FERNÁNDEZ, Pedro A.; HERNÁNDEZ-NAVARRO, Miguel Á.; PÉREZ PÁEZ, Julián; y otros (2006): La práctica de la crítica: El artista y el escritor críticos de arte. Murcia, Ed. Asociación Murciana de Críticos de Arte.

DANTO, Arthur C. (1999): Después del Fin del Arte. Barcelona, Paidós.

FREELAND, Cynthia (2004): Pero ¿esto es arte? (Una introducción a la teoría del arte). Cuadernos Arte Cátedra. $2^{\mathrm{a}}$ Edición, Madrid.

FISCHER, Ernst (2001): La necesidad del arte. Barcelona, Península.

GABLICK, Suzi (1987): ¿Ha Muerto el Arte Moderno?. Madrid, Ed. Hermann Blume.

GUASH, Ana María (2000): El arte último del siglo XX. Del posminimalismo a lo multicultural, Madrid, Alianza Forma.

GUASH, Ana María (2007): La crítica dialogada: entrevistas sobre arte y pensamiento actual (2000-2007). Murcia, Cendeac.

HAUSER, Arnold (1975): Introducción a la Historia del Arte. Teorías del arte: tendencias y métodos de la crítica moderna. Madrid, Guadarrama.

JARAUTA, Francisco (2005): Foro de la Mundialización / Agenda de la Globalización: Problemas. Murcia, Fundación Cajamurcia.

LUHMANN, Niklas (2000): La realidad de los medios de masas. Barcelona, Anthropos,

MAILLARD, Chantal (2009): Contra el Arte y otras imposturas. Valencia, Pre-textos.

MELLING, David J (1991): Introducción a Platón. Madrid, Alianza Editorial.

MOXEY, Keith (2004): Teoría, práctica y persuasión. Estudios sobre historia del arte. Barcelona, Ediciones del Serbal.

NAVARRETE, Ana (1993): La crítica de la modernidad como crítica a la autonomía del arte. Cuenca, Universidad de Castilla la Mancha.

ORTEGA Y GASSET, José (2005): La deshumanización del arte y otros ensayos de estética. Madrid, Espasa-Calpe, Colección Austral. 
OTEIZA, Jorge (1994): Quosque Tamdem ...!. Pamplona, Ed. Pamiela.

PARREÑO, José María (2006): Un arte descontento: Arte, compromiso y crítica cultural en el cambio de siglo. Murcia, Cendeac.

PLAZAOLA, Juan (2003): Modelos y Teorías de la Historia del Arte. San Sebastián, Universidad de Deusto.

RILKE, Rainer Maria (2006): Cartas a un joven poeta. Madrid, Alianza Editorial.

ROSS, David (2001): Teoría de las Ideas de Platón. Madrid, Cátedra.

RUIZ LÓPEZ, Juan Ignacio (2004): El sistema del arte en Murcia, Espacios, politicas, y estructuras en el arte del siglo XX. Museo de la Ciudad. Murcia, Ayuntamiento de Murcia. Novograf.

SAURA MIRA, Fulgencio (1998): "En Memoria de Don Manuel Jorge Aragonenes". Cangilón, núm. 16, Septiembre, pp. 41-42.

SCHOPENHAUER, Arthur (1998): El amor, las mujeres y la muerte. Barcelona, Ed. Edicomunicación S.A., Clásicos Universales, Colección Fontana.

SUBIRATS, Eduardo (1989): El final de las vanguardias. Barcelona, Ed. Anthropos.

TÀPIES, Antoni (1989): La Realidad como Arte. Por un arte moderno y progresista. Murcia, Comisión de Cultura del Colegio Oficial de Arquitectos Técnicos, Galería-librería Yerba, Consejería de Cultura y Educación.

TOLSTOI, León (1998): ¿Qué es el Arte?. Madrid, Ed. Alba.

VENTURI, Lionello (2004): Historia de la Crítica de Arte. Barcelona, Random House Mondadori, S.A.

VV.AA. (1999): Historia de las ideas estéticas y de las teorías artísticas contemporáneas Director: Valeriano Bozal. Volumen II. Madrid, Visor.

WATZLAWICK, Paul (1991): Teoría de la comunicación humana. Barcelona, Herder. WILDE, Oscar (1997): "El arte del ingenio", libro incluido en El retrato de Dorian Gray. Barcelona, Ed. Optima. 